\title{
Anesthetic Management of an Elderly Patient with Permanent Pacemaker posted for Fixation of Tibial and Radial Fracture
}

\author{
${ }^{1}$ Praveen Halgunaki, ${ }^{2}$ GS Karthik, ${ }^{3}$ Rangalakshmi, ${ }^{4} \mathrm{H}$ Sahajananda
}

\begin{abstract}
Cardiac patients with pacemaker presenting for noncardiac surgery pose a considerable challenge to the anesthesiologists. In the United States it is said that there are more than 500,000 patients with pacemaker and every year more than 115,000 devices are implanted. Intraoperative care of the pacemaker as well as understanding its anesthetic implication is crucial in the management of these high-risk patients. We hereby present a case of an 85-year-old male posted for plating of tibial fracture with k-wiring of radius fracture who had permanent cardiac pacemaker in situ.
\end{abstract}

Keywords: Invasive cardiac monitoring, Pacemaker, Regional anesthesia.

How to cite this article: Halgunaki P, Karthik GS, Rangalakshmi, Sahajananda H. Anesthetic Management of an Elderly Patient with Permanent Pacemaker posted for Fixation of Tibial and Radial Fracture. J Med Sci 2015;1(4):77-79.

Source of support: Nil

Conflict of interest: None

\section{INTRODUCTION}

With the advent of cardiac pacemakers, the treatment of patients with cardiac arrhythmias has been dramatically improved. In 1958, pacemaker was implanted for the first time. ${ }^{1}$ Due to steady progress in device technology and software applications, many new multiprogrammable pacemakers have been released into the markets. This has also increased the potential indications for pacing. Lifestyle and comfort of this group of high-risk patients have been drastically changed.

Pacemakers are being used with greater frequency for both conduction disorders and arrhythmias. Intraoperative care of the pacemaker as well as understanding its anesthetic implications is important in the management of these patients. ${ }^{2,3}$

\footnotetext{
${ }^{1}$ Postgraduate Student, ${ }^{2}$ Associate Professor, ${ }^{3}$ Professor ${ }^{4}$ Professor and Head

${ }^{1-4}$ Department of Anesthesiology, RajaRajeswari Medical College and Hospital, Bengaluru, Karnataka, India

Corresponding Author: H Sahajanands, Professor and Head Department of Anesthesiology, RajaRajeswari Medical College and Hospital, Bengaluru, Karnataka, India, Phone: +919448085401 e-mail: sahaj_anand@hotmail.com
}

\section{CASE REPORT}

An 85-year-old male weighing $50 \mathrm{~kg}$ was scheduled for tibial fracture plating along with k-wiring of radius fracture. He had undergone permanent pacemaker insertion (Boston Scientific-ALTURA50-S501-DDD) 3 years back for symptomatic bradycardia and syncope. He had medical history of hypertension since 5 years and advised to take regularly Tab. Amlodepine $5 \mathrm{mg}$ and Tab. Losartan $50 \mathrm{mg}$ once daily. He was a chronic smoker 2 packs of beedies/day $\times 45$ years. Effort tolerance was more than four metabolic equivalents (METS). His general and systemic examination and routine blood investigations were within the normal limits. But pulmonary function tests (PFTs) showed mild obstructive pattern. Electrocardiogram (ECG) (Fig. 1) showed pacemaker rhythm and echocardiography was normal. Chest X-ray (Fig. 2) showed pacemaker with impulse generator. Thorough interrogation with competent authority was carried out for obtaining pacemaker details like when it was implanted, battery life, mode, effect of magnet, baseline rate, etc. Our patient baseline heart rate was $60 /$ minute and on dual pacing (atrial and ventricular pacing), dual sensing (atrial and ventricular sensing), dual response and rate-adaptive (DDD-R) mode. Informed consent was taken for general anesthesia, invasive monitoring, blood transfusion, and postoperative intensive care unit (ICU) care. Patient was premedicated with Tab. Midazolam and was kept nil per orally overnight. The cardiologist opinion was sought and requested to be on call for further help, if need be.

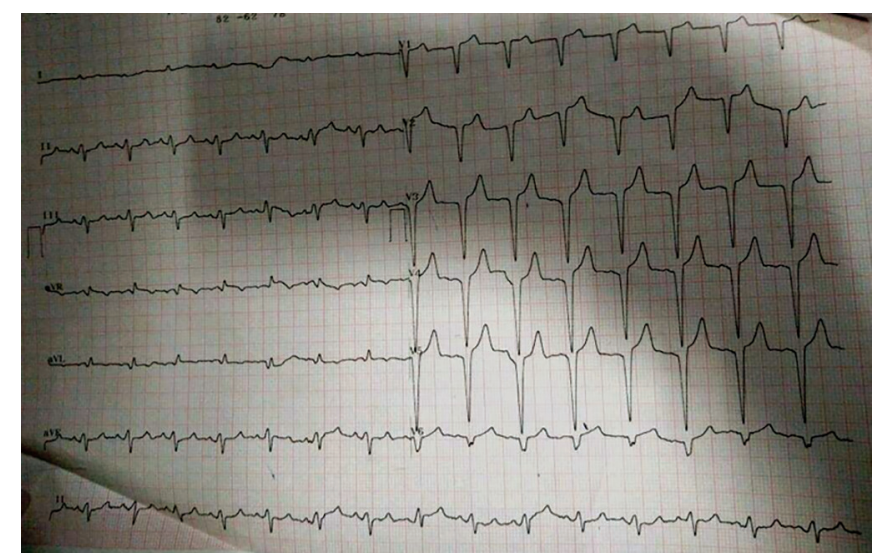

Fig. 1: Electrocardiogram showing the pacemaker rhythm 


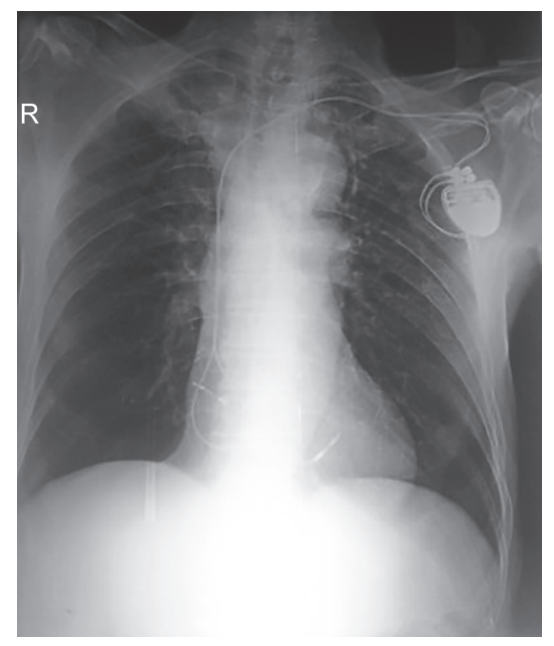

Fig. 2: X-ray of chest showing pacemaker in situ

\section{ANESTHETIC TECHNIQUE}

On the day of surgery the pacemaker mode was changed to asynchronous fixed mode, i.e., ventricle paced, none sensed, no response (VOO), and the baseline heart rate was reset from 60 to $80 /$ minute. 18G intravenous (IV) cannula and arterial cannulae were secured under local anesthesia and beat-to-beat blood pressure (BP) was recorded. Physiological monitoring included ECG, pulse oxymetry, capnography, and temperature. After preoxygenation for 3 minutes with $100 \%$ oxygen, anesthesia was induced with injections Midazolam $50 \mu \mathrm{g} / \mathrm{kg}$, injections Fentanyl $2 \mu \mathrm{g} / \mathrm{kg}$, and injections Etomediate $0.3 \mathrm{mg} / \mathrm{kg}$. Intubation with appropriate-sized cuffed portex tube was achieved after Vecuronium $0.1 \mathrm{mg} / \mathrm{kg}$. Anesthesia was maintained with intermittent positive pressure ventilation using $\mathrm{O}_{2}+\mathrm{N}_{2} \mathrm{O}+$ Isoflurane and divided doses of Injection Vecuronium bromide. During intraoperative period care was taken to maintain normal BP, normocapnea, and normal temperature. A bipolar cautery was used with return pad kept below left leg. Multimodal analgesia was administered by using injections Paracetamol Ig IV, injections Fentanyl $50 \mu \mathrm{g} I V$, and wound was infiltrated with $10 \mathrm{~mL}$ of $1.5 \%$ Injection Lidocaine.

After completion of surgery neuromuscular block was reversed with injections Glycopyrollate $10 \mu \mathrm{g} / \mathrm{kg}$ and injections Neostigmine $0.05 \mathrm{mg} / \mathrm{kg}$. Patient was extubated when patient was awake with adequate muscle tone and power. Then she was shifted to ICU where her heart rate was reset to DDD mode with heart rate of 80 beats/ minute. Diclofenac sodium $75 \mathrm{mg}$ IV was administered for postoperative analgesia and care was taken to prevent shivering. Patient was in the ICU for 48 hours, and later she was shifted to the ward. Later her stay was uneventful. On the 5th day was discharged home.

\section{DISCUSSION}

A pacemaker has an impulse generator and leads to carry the electrical impulse to the patient's heart. Pacemaker leads can be unipolar or bipolar or multipolar. They are connected to the heart chambers through vena cava or on the surface of heart epicardially. Unipolar leads are more sensitive to the effects of electromagnetic interference and produce larger spikes on ECG. Pacemaker has generic codes which are mentioned in Table 1.

There are several indications for pacemaker, which include symptomatic sinus node disease, long QT interval syndrome, and cardiomyopathies. In our patient, pacemaker was implanted for bradycardia and repeated attacks of syncope.

Preanesthetic management of a patient with pacemaker includes evaluation and optimization of coexisting disease. Communication with the programmer is a reliable method for knowing battery life, battery impendence, performance of the leads, and appropriateness of current settings.

Necessary reprogramming of the pacemaker is the safest way to avoid intraoperative complications. Reprogramming a pacemaker to asynchronous mode at a rate more rapid than the patient's baseline rate helps to avoid sensing during electromagnetic interference. Any responses to rate and other enhancements should be promptly disabled. In our patient pacemaker was reset from DDD to VOO mode and heart rate was reset from 60 to $80 /$ minute before induction of anesthesia.

The anesthetic technique should be used according to the needs of the patient. General anesthesia with both narcotic and inhalational techniques can be used successfully. These anesthetic agents do not affect the current and voltage settings and thresholds of the pacemaker. ${ }^{5}$ Causes for inappropriately triggering of the pacemaker by inhibition or stimulation should be avoided. ${ }^{6}$ Examples are skeletal myopotentials, electroconvulsive therapy, suxamethonium fasciculations, tremors like myoclonic movements, or direct muscle stimulation. The muscle fasciculation induced by depolarizing relaxants like suxamethonium can be avoided by using other group of

Table 1: Generic codes for pacemaker ${ }^{4}$

\begin{tabular}{lllll}
\hline I Pacing & II Sensing & III Response & IV Programmability & V Tachycardia \\
\hline O-None, A-Atrium & O-None, A-Atrium & O-None, A-Atrium & O-None, C-Communicating & O-None, S-Shocks \\
A-Atrium, V-Ventricle & V-Ventricle, D-Dual (A+V) & I-Inhibited, T-Triggered & P-Simple programmable & P-Pacing, D-Dual (S+P) \\
$\begin{array}{ll}\text { D-Dual (A+V) (A+V) } \\
\text { S-Simple }\end{array}$ & $(\mathrm{A}+\mathrm{V})$ S-Simple & D-Dual (I+T) & M-Multi programmable & \\
\hline
\end{tabular}


muscle relaxants or by priming technique. It is better to avoid using etomidate and ketamine as these can cause myoclonic movements. ${ }^{7}$ One should monitor pacemaker function before and after starting mechanical ventilation, to know the dislodgement of pacemaker leads by positive pressure ventilation ${ }^{8}$ or by nitrous oxide. If the pacemaker ${ }^{9}$ has responsive mode option, rate responsiveness should be deactivated before anesthesia and surgery. If it is unavoidable, the mode of rate responsiveness must be known so that conditions causing changes in paced heart rate can be avoided. Shivering and fasciculations should be avoided if the pacemaker is rate responsive, and ventilation should be controlled and kept constant in case of "minute ventilation" rate responsive; hypothermia or hyperthermia must be avoided in "temperature" rateresponsive pacemakers. ${ }^{10}$

Intraoperative patient monitoring includes ability to detect pacing discharge by ECG monitoring, to ensure that paced electrical activity is converted to mechanical systole. Backup pacing or defibrillation facilities should be available. Surgeons should be advised to use a bipolar cautery. If bipolar cautery is unavailable, monopolar cautery pad must be placed close to site of surgery to prevent pacemaker malfunction. Fluctuations in temperature must be avoided by keeping it constant in case "temperature" rate-responsive pacemakers are used. 11,12

Postoperative shivering should be avoided to prevent dislodgement of pacing leads. Surgical procedures with the use of monopolar electrosurgical units like lithotripsy, ${ }^{13}$ transurethral resection of prostate, magnetic resonance imaging, ${ }^{14}$ and electroconvulsive therapy require special precautions. Postopertaively the settings of the pacemaker should be reprogrammed to their original setting.

\section{CONCLUSION}

General anesthesia with invasive cardiac monitoring is a reasonable choice for the elderly patients with a permanent pacemaker and severe co-morbid conditions coming for complex orthopedic surgery. In the operation rooms, transcutaneous pacing and transvenous pacing facility should be made available. Optimization of the patient preoperatively, careful monitoring, acceptable pain relief, and good postoperative care is the key for successful management of these patients.

\section{REFERENCES}

1. Hayes DL, Zipes DP. Cardiac pacemakers and cardioverterdefibrillator. In: Braunwald E, editor. Heart disease. 6th ed. Philadelphia (PA): WB Saunders; 2001. p. 7775-7814.

2. Stone ME, Salter B, Fischer A. Perioperative management of patients with cardiac implantable electronic devices. Br J Anaesth 2011;107 (Suppl 1):i16-i26.

3. Diprose P, Pierce JMT. Anaesthesia for patients with pacemakers and similar devices. Br J Anaesth 2001;1(6):166-170.

4. Bernstein AD, Camm AJ, Fischer JD, Fletcher RD, Mead RH, Nathan AW, Parsonnet V, Rickards AF, Smyth NPD, Sutton R, et al. The NASPE*/BPEG** defibrillator code. PACE 1993 Sep;16:1776-1780.

5. Atlee JL, Bernstein AD. Cardiac rhythm management devices (part II): perioperative management. Anesthesiology 2001 Dec;95:1492-1506.

6. Atlee JL. Cardiac pacing and electroversion. In: Kaplan JA, editor. Cardiac anesthesia. 4th ed. Philadelphia (PA): WB Saunders; 1999. p. 959-989.

7. Sethuran S, Toff WD, Vuylsteke A, Solesbury PM, Menon DK. Implanted cardiac pacemakers and defibrillators in anaesthetic practice. Br J Anaesth 2002 May;88(5):627-631.

8. Thiagarajah S, Azar I, Agres M, Lear E. Pacemaker malfunction associated with positive pressure ventilation. Anesthesiology 1983 Jun;58(6):565-566.

9. Lamas GA, Rebecca GS, Braunwald NS, Antman EM. Pacemaker malfunction after nitrous oxide anesthesia. Am J Cardiol 1985 Dec 1;56(15):995.

10. Chien WW, Foster E, Phillips B, Schiller N, Griffin JC. Pacemaker syndrome in a patient with DDD pacemaker for long QT syndrome. Pacing Clin Electrophysiol 1991 Aug;14(8):1209-1212.

11. Mehta Y, Swaminathan M, Juneja R, Saxena A, Trehan N, Atlee JL. Noncardiac surgery and pacemaker cardioverterdefibrillator management. J Cardiothorac Vasc Anesth 1998 Apr;12(2):221-224.

12. Gregoratos G, Abrams J, Epstein AE, Freedman RA, Hayes DL, Hlatky MA, Kerber RE, Naccarelli GV, Schoenfeld MH, Silka MJ, et al. ACC/AHA/NASPE 2002 Guideline update for implantation of cardiac pacemaker and anti arrhythmia devices - summary article (a report of the ACC/AHA/NASPE committee to update the 1998 pacemaker guidelines). J Am Coll Cardiol 2002 Nov;40(9):1703-1719.

13. Drach GW, Weber C, Donovan JM. Treatment of pacemaker patients with extracorporeal shock wave lithotripsy: experience from 2 continents. J Urol 1990 May;143(5): 895-896.

14. Achenbach S, Moshage W, Diem B, Bieberle T, Schibgilla V, Bachmann K. Effects of magnetic resonance imaging on cardiac pacemakers and electrodes. Am Heart J 1997 Sep;134(3):467-473. 